\title{
A method to analyse urban heatwaves. Case study - Bucharest City (Romania)
}

\author{
Daniela-Elena Gogoașe-Nistoran ${ }^{1,}$, Daniel-Marian Antohe, Ioana Opriș ${ }^{2}$ and Cristina- \\ Sorana Ionescu ${ }^{1}$ \\ ${ }^{1}$ University Politehnica of Bucharest, Faculty of Power Engineering, Dept. of Hydraulics, Hydraulic \\ machines and Environmental engineering \\ ${ }^{2}$ University Politehnica of Bucharest, Faculty of Power Engineering, Dept. of Energy Production and \\ use
}

\begin{abstract}
Long-term variation of hourly air temperature obtained from Open Weather, Romania, was analysed in the center of Bucharest city, over a period of 40 years (1980-2020). A computer program to extract summer heatwaves within the study period was written. Analysing the results an extreme heatwave scenario has been defined within the context of climate change and urban influence, to be used in future air and water temperature models.
\end{abstract}

\section{Introduction}

During the last decades, Europe has faced important heatwaves, that present an increasing trend since 1970s, both in magnitude and frequency [1, 2, 3, 4, 5]. Similar trends were as well registered in Romania [6, 7, 8, 9].

The impact of excessive warming on human health and the environment is particularly stronger during summer time within and around city areas. This is due to anthropic activities, that generate the urban heat island effect, giving rise to a substantial air temperature increase throughout summers. Among the most important factors known to trigger the urban island effect are: extended built areas and heavy concentration of pavement and impervious surfaces that absorb and retain heat, intensified road transport, lack of green areas, waste heat through increased use of air conditioning systems, threedimensional (3D) urban geometry $[10,11,12,13]$ etc.

There are different definitions of heatwaves, which are considered very hot periods for the local climate. The World Meteorological Organization (WMO) defines a heatwave as a period during which the daily maximum temperature exceeds by $5^{\circ} \mathrm{C}$ for more than five consecutive days the average multiannual maximum temperature.

Depending on local climate, each country may use different definitions for determining heatwaves. In Romania two threshold values are used to define a heatwave lasting at least five consecutive days, such as : the daily maximum temperatures over $35^{\circ} \mathrm{C}$ and the night maximum ones over $20^{\circ} \mathrm{C}$.

\footnotetext{
* Corresponding author: daniela.nistoran@upb.ro
} 
Furthermore, in Meteorology and particularily in the urban environments, a temperature-humidity index (THI) is used to quantify the human "felt" heatwave. The comfort - associated THI index takes also into account both temperature and the relative humidity. The latter is an important parameter, having a negative influence on the real feel of high temperature perception.

In Bucharest, summers have become increasingly hotter during the last two decades [8]. This has also affected the water temperature of the water bodies within the city, such as the Morii Reservoir which feeds the Dambovița canal and Colentina River. River managers had to cope with the increasing spreading of vegetation bursts occurring during summers along Dambovi'a canal, during the last few years. In august 2017, after a prolonged heatwave local media reported a large quantity of fish died in the Morii Reservoir due to high temperatures. Thus, heatwaves also affect fauna and flora, not only people within the urban environment [14]. However, scientific papers dealing with these late changes on Dambovița River are missing.

The objective of the paper is to analyse the heatwaves in Bucharest city, based on a specially designed computer program in order to define the air and temperature and humidity variation during an extreme heat-wave scenario. The program allows to identify heatwaves characteristics such as their frequency, duration, pattern, maximum temperature, humidity variation, period of occurrence as well as to compute the THI. These data are useful for a water river temperature modeling.

\section{Data}

Hourly air temperatures were downloaded from OpenWeather.com in the centre of Bucharest city, at Piaţa Unirii (Unirii Square, $26.086^{\circ} \mathrm{E}$ and $44.438^{\circ} \mathrm{N}$ ), for the period 1980 - 2020. OpenWeather collects and processes weather data from a vast network of over 40,000 weather stations and from meteorological broadcast services worldwide, such as satellites, radars and even uses global and local weather models (set of algorithms, to improve its quality and accuracy) [15]. The accuracy and quality of OpenWeather temperature data has been evaluated for 371 major cities, including Bucharest $\left(26.10626^{\circ} \mathrm{E}\right.$ and $44.43225^{\circ} \mathrm{N}$ ) and found to have a mean absolute error (MAE) between two stations being of $0.5^{\circ} \mathrm{C}$, a reliability of $90-100 \%$ and a mean accuracy of $99 \%$.

By fitting the temperature variation with a linear function, an average increase of $1.5^{\circ} \mathrm{C}$ over the 40 -years study period was noticed. In Fig. 1 is represented this variation over 30 years, from 1990-2020 only, since yearly heatwaves over $35^{\circ} \mathrm{C}$ became more frequent. One may observe that after the year 2000, maximum summer temperatures reached and even surpassed $40{ }^{\circ} \mathrm{C}$ (in 2000, 2007, 2012 and 2017).

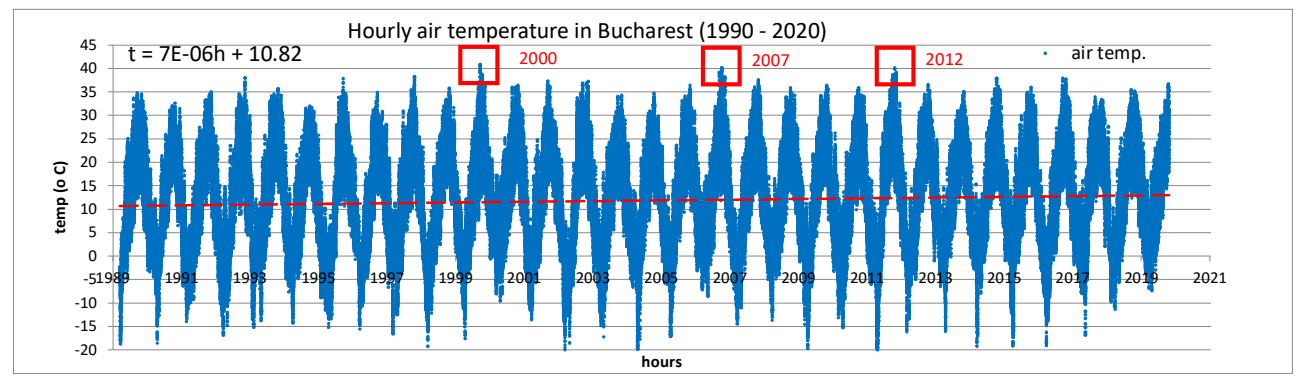

Fig. 1. Hourly air temperatures in Bucharest City centre over 30 years (1990-2020) (satellite data from Openweather.com at $2 \mathrm{~m}$ from ground) 


\section{Method}

The computer program is based on the Romanian definition of the heatwave. Its flow chart is shown in Fig. 2. The main steps of the conceptual model it relies on are:

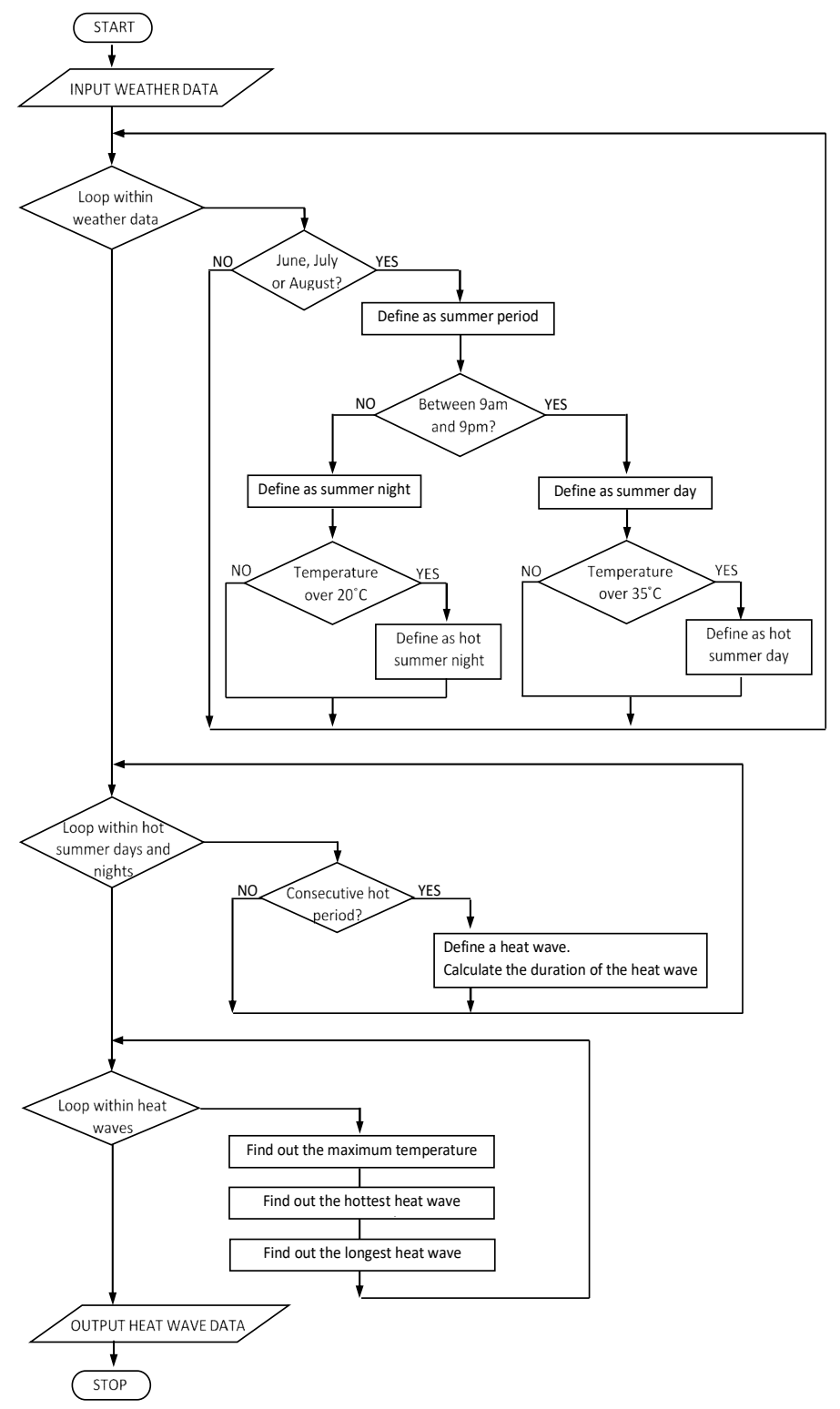

Fig. 2 Flow chart of the computer program

1. Find summer periods from 15 June to 15 September. 
2. Create two line vectors with air temperature data during days and nights, defined between 9:01 - 21:00 and 21:01 - 9:00, respectively.

3. Find dates with daily temperatures over $35^{\circ} \mathrm{C}$ and nights with temperatures over $20^{\circ} \mathrm{C}$ of the two vectors.

4. Eliminate duplicate data

5. Merge the two-line vectors from step 3 into one with days and nights and create a new line vector with at least 5 consecutive days satisfying both conditions of step 3.

6. Find years with heatwaves.

7. Compute each heatwave duration.

8. Find the longest heatwave.

9. Find maximum temperature for each heatwave.

10. Find most extreme heatwave.

11. Read relative humidity corresponding to each heatwave.

12. Compute temperature-humidity index $(T H I)$ with the formula given by [16 ]

$$
T H I=(1.8 \cdot t+32)-(0.55-0.0055 \cdot R H) \cdot[(1.8 \cdot t+32)-58]
$$

where $R H$ is the relative humidity in $\%$ and $t$ is the air temperature in ${ }^{\circ} \mathrm{C}$. One may observe from this relation that high THI units correspond to high relative humidity values, which makes temperature feel hotter than it is. Values under 65 are in the confort zone, between 65-80 fall into the critical zone, whereas values over the threshold of 80 units are in the disconfort zone responsible for high impact on human health.

\section{Results and discussions}

During the studied period, the program identified 6 heatwaves, all of them occurring during the months of July and August. In Fig. 3 (a - f) are represented the temperature, relative humidity and THI index for these 6 heatwaves.

One may observe that temperature and relative humidity daily sinusoidal variations are inversely proportional. Also, by fitting these variables with second degree polynomial functions over a heatwave, one may observe that the mean temperature variation is also inverse to the mean relative humidity. The points of intersection of these fitting functions define the start and end of the heatwaves. This is a new way of finding the duration of a heatwave.

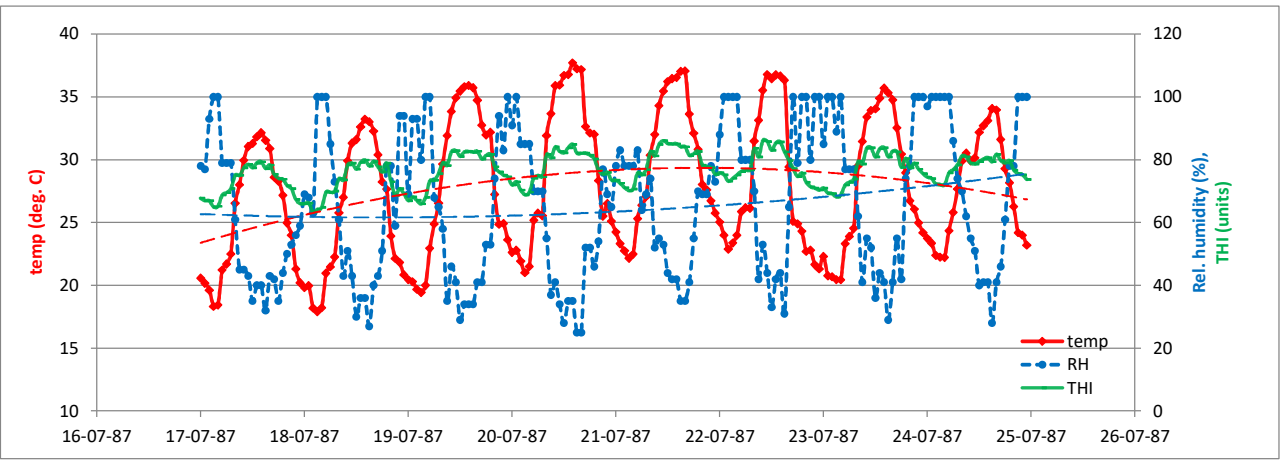

a) 


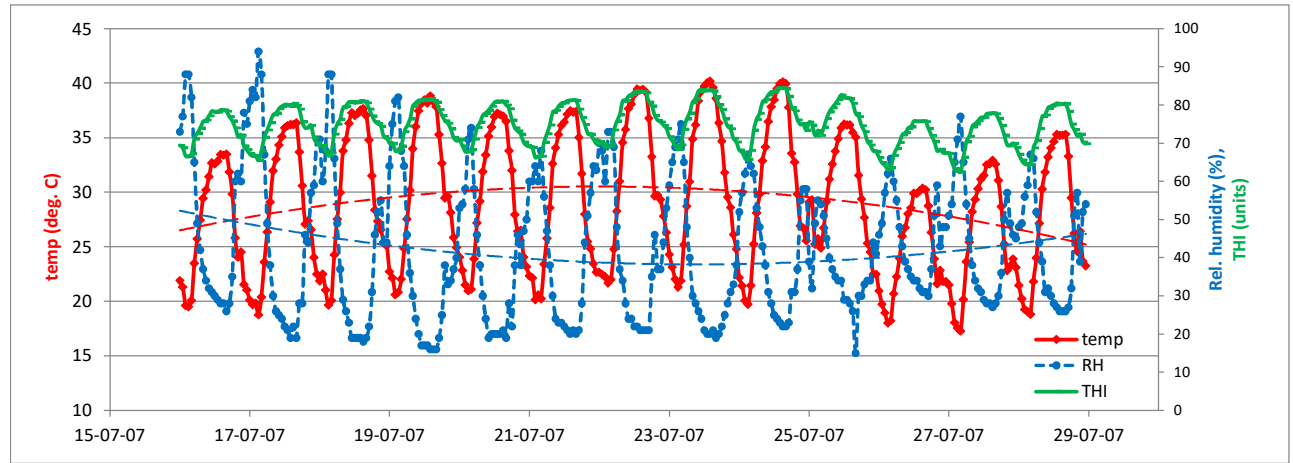

b)

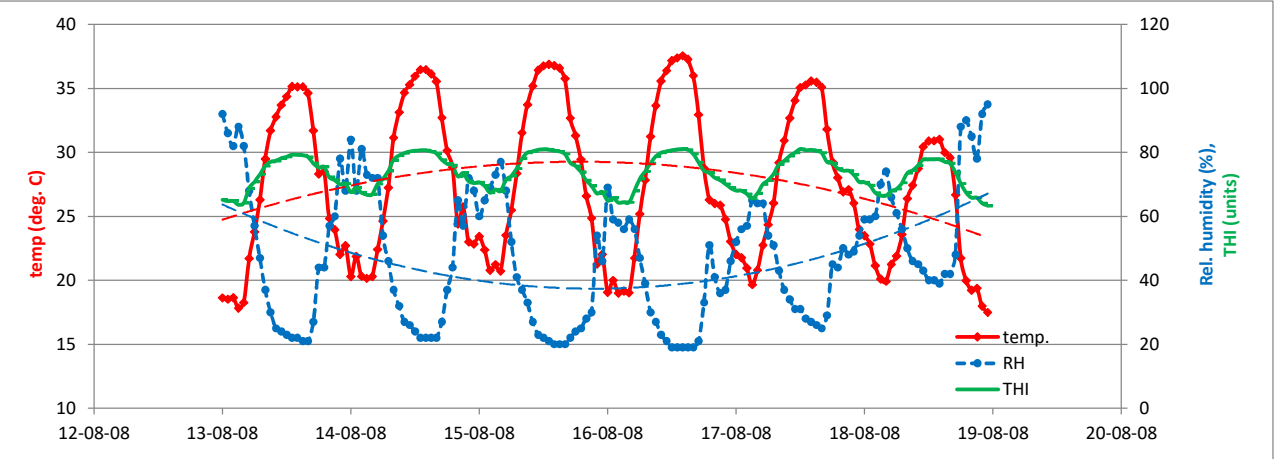

c)

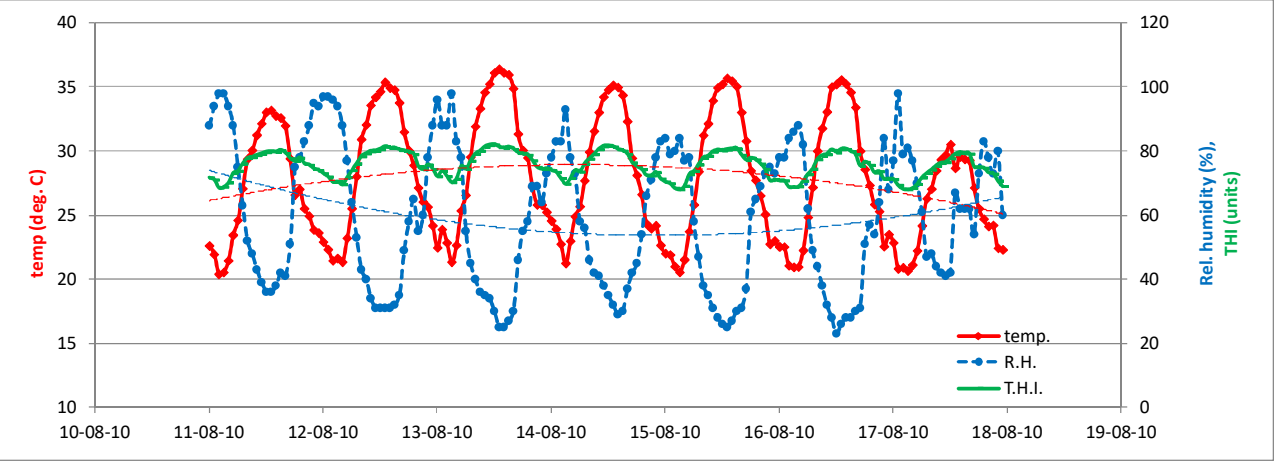

d)

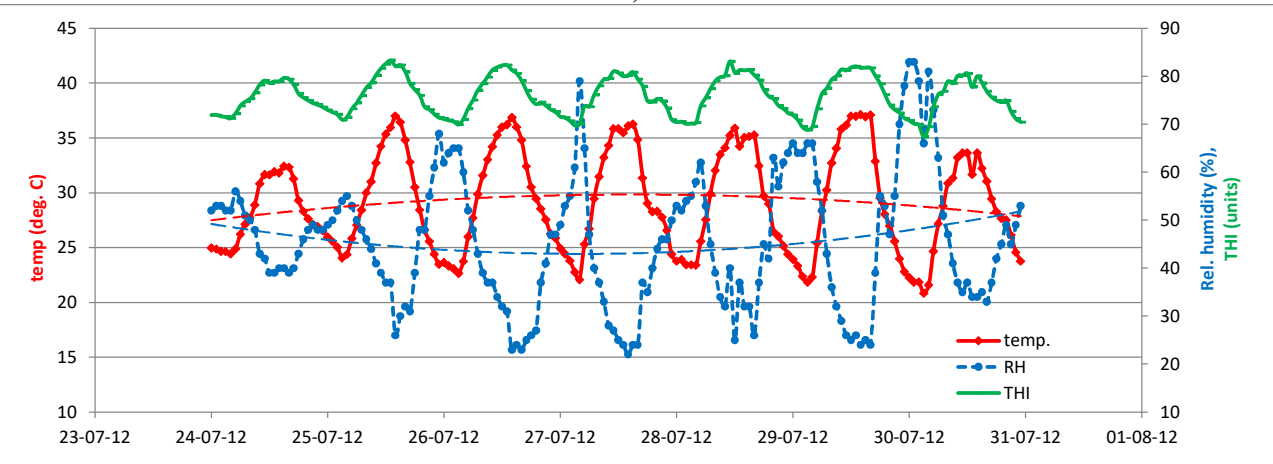

e) 


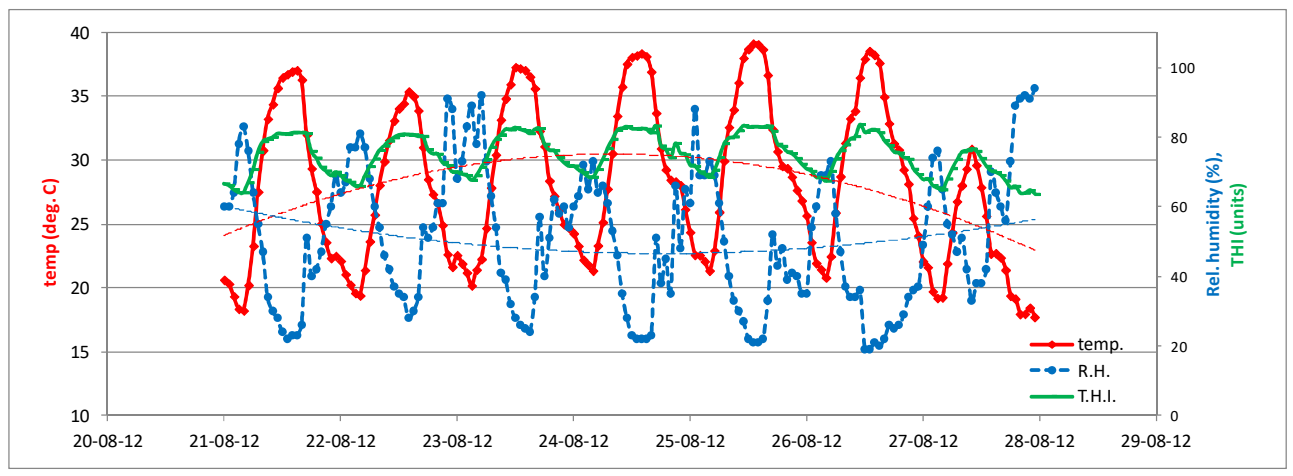

f)

Fig. 3 a) - f) The six heatwaves (temperature, Relative humidity and Temperature - humidity index variation) identified within the 40 -years study period in a) 1987 , b) 2007 , c) 2008 , d) 2010 , e) July 2012 and f) August 2012,

One may see from Fig. 3 that for all the identified heatwaves the range of calculated THI index overpassed the critical threshold of 80 units during several days.

Table 1 presents the most important parameters of the heatwaves. The temperaturehumidity index was calculated with the formula (1).

Tab. 1 The most important characteristics of the six identified heatwaves

\begin{tabular}{|r|l|c|c|c|c|}
\hline $\begin{array}{l}\text { Crt. } \\
\text { No }\end{array}$ & Period of time & duration & Max. temp & $\begin{array}{c}\text { Relative } \\
\text { humidity } \\
\text { range }\end{array}$ & $\begin{array}{c}\text { Range of } \\
\text { THI }\end{array}$ \\
\hline 1 & $19-24.07 .1987$ & 6 & 37.7 & $25-100$ & $63.4-86$ \\
\hline 2 & $17-26.07 .2007$ & 10 & 40.2 & $15-94$ & $62.4-84.5$ \\
\hline 3 & $13-18.08 .2008$ & 6 & 37.5 & $19-95$ & $63.3-81$ \\
\hline 4 & $12-17.8 .2010$ & 6 & 36.42 & $23-98$ & $68-82$ \\
\hline 5 & $\begin{array}{c}25-30.07 .2012 \\
\text { units }\end{array}$ & 6 & 37.12 & $22-83$ & $67-83.3$ \\
\hline 6 & $\begin{array}{c}21-27.08 .2012 \\
\text { Values } \\
\text { considered for } \\
\text { the extreme } \\
\text { scenario }\end{array}$ & 7 & 39.13 & $19-98$ & $61-83.7$ \\
\hline
\end{tabular}


The longest and the hottest heatwave is the one from July 2007. The year 2007 was also found by [16] and [17] to be the hottest year since measurements are performed in Romania. However, by analysing the heatwaves of the years 2007, 2012 and 2015, [17] showed that 2012 was an extreme hot summer, particularily for the Bucharest study area, due the extent over nearly two months (during July and August) of the high temperatures coupled with lack of precipitations.

\section{Conclusions}

The values and ranges of the main features of the six identified heatwaves in Table 1 were used to build a 7-days extreme heatwave, that will be used as a worst-case scenario in future modeling air and / or water temperature time variation. Temperature and relative humidity variation were build as simple sinusoidal functions.

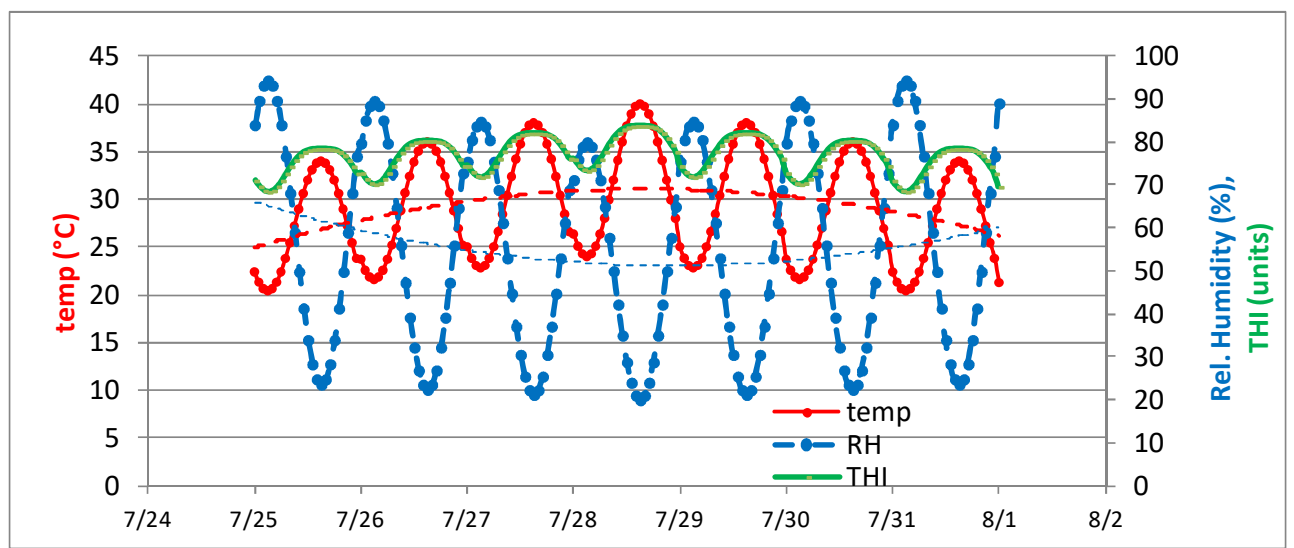

Fig. 4 The 7-day extreme heatwave scenario built with sinusoidal functions, after analysing the results of the heatwaves in Bucharest (extracted over a 40 year-period with the proposed program): air temperature, relative humidity and THI

The necessity of writing present analysis program arose from not finding such a readymade customizable tool. Therefore, one of the advantages of the computer program built for the present study is that it can be used for any period of time, any location and any definitions of the heatwave to analyse their frequency duration and patterns. The current disadvantage is does not have a user-friendly interface, needing basing programming knowledge.

Also, by presenting the flowchart and the steps of the conceptual model, it may be written in any programming language. However, one drawback is that the results (temperature and humidity over the resulted periods) are easier plotted, processed and formatted by using another specialised graphical software.

The new method of finding the duration of a heatwave by fitting the temperature and relative humidity variations with second order polynomial functions may also be used for other analyses.

\section{References}

1. S. Russo, J. Sillmann, E. M. Fischer, Environ. Res. Lett. 10, 124003 (2015)

2. R. Zhang, C. Sun, J. Zhu, Re. Zhang, Weijing L., npj Clim. Atmos. Sci. 3, 7 (2020) 
3. C. Schär, P. Vidale, D. Luthi, C. Frei, C. Haberli, M. Liniger, C. Appenzeller, Nature 427, 332 (2004)

4. P. Stott, D. Stone, M. Allen, Nature 432, 610 (2004)

5. P.M. Della-Marta, J. Luterbacher, H. von Weissenfluh, E. Xoplaki, M. Brunet, H. Wanner, Clim. Dyn. 29, 251 (2007)

6. A.-E. Croitoru, A. Piticar, A.F. Ciupertea, C.F. Roşca, Glob. Planet. Change 146, 109 (2016)

7. C.-S. Dragotă, L.-E Havriş, In Proceedings of Air and water-Components of the Environment, Cluj, Romania, 15, 20-22 March 2015.

8. A.-E. Croitoru, R.I. Antonie, A. Rus, In Proceedings of the 14th International Multidisciplinary Scientific GeoConference, pp. 375-382 (SGEM 2014)

9. L. Sfîcă, A. E. Croitoru, I. Iordache, A. F. Ciupertea, Atmosphere 8(3), 50 (2017)

10. S. Cheval, A. Dumitrescu, Theor Appl Climatol, 121, 631 (2015)

11. Y. H. Ryu, J. J. Baik, J. Appl. Meteorol. Climatol., 5, 842 (2012)

12. K. Ward, S. Lauf, B. Kleinschmit, W. Endlicher, Sci. Total Environ., 569-570, 527 (2016)

13. M. Nastran, M. Kobal, K. Eler, Urban. For. Urban. Green., 37, 33 (2019)

14. L. Zaharia, G. Ioana-Toroimac, O. Cocoș, F. A. Ghiță, E. Mailat, Urbanization effects on the river systems in the Bucharest City region (Romania), Ecosyst. Health Sustain, 2, e01247 (2016)

15. OpenWeather, https://openweathermap.org/accuracy-and-quality, accessed May 3, 2021

16. L. Leontie, A. Timofte, D. C. Bostan, S. Bostan, Present Environment and Sustainable development, 2, 23 (2008)

17. V. Dima, A. Irimescu, F., Georgescu, D. Mihăilescu, Valuri de căldură în România, Ed. Printech, București, 2016 